\title{
1 \\ Environmental Informatics Towards a new Discipline in Applied Computer Science for Environmental Protection and Research
}

\author{
B. Page \\ University of Hamburg, Department of Informatics \\ Vogt-Koelln-Str. 30, D-22527 Hamburg, Germany
}

\begin{abstract}
Environmental problem solving is very much an information processing activity handling a wide range of environmental data from various sections and of different structure. In this review paper a typology of environmental processing systems is given and the background, terminology and main issues of a novel discipline of applied Computer Science - more recently named as Environmental Informatics - introduced. A selected Environmental Informatics project is presented dealing with the development of a knowledge-based simulation frame system supporting modeling and simulation of environmental systems. It was employed as prototyping tool for designing a specific table-based modeling system for road traffic emission analysis. Finally the emerging research scene of Environmental Informatics in Germany and on the international scale is discussed.
\end{abstract}

\section{INTRODUCTION: THE ROLE OF ENVIRONMENTAL INFORMATION PROCESSING}

The protection of our environment is one of the greatest challenges in our industrialized societies. This challenge is addressing politics, economy as well as technology and research. It is clear that the various problems in environmental protection, environmental planning, research and engineering can be only solved on the ground of a comprehensive and reliable information basis. State and dynamics of the environment are described by biological, physical, chemical, geological, meteorological, or socio-economical data. This data is time and space dependent and addresses past or current states. The processing of this data and the production 
of information on the environment, on its stress factors and mutual influence mechanisms are fundamental for any kind of environmental planning and preventive measures. Therefore environmental problem solving is mainly an information processing activity handling a wide range of environmental data. Solutions to our environmental problems are strongly dependent on the quality of accessable information sources. Certainly, information is a very critical factor in making decisive political actions and in changing people's attitudes on the environment.

Meanwhile the application of information technology has become absolutely essential in the environmental domain for providing the required environmental information on the appropriate level of detail, completeness, accuracy and speed. This information on environmental aspects is just as important as basis for decisions on actions in environmental protection as for gaining knowledge in environmental research. It includes descriptions of the current state of the environment, prognoses on future environmental developments as well as assessments on current or future states.

In Figure 1 it is indicated, how human caused environmental burdens and damages could be couteracted with computerized environmental data and information for the public, the economy, the administration and politics by means of feedback effects.

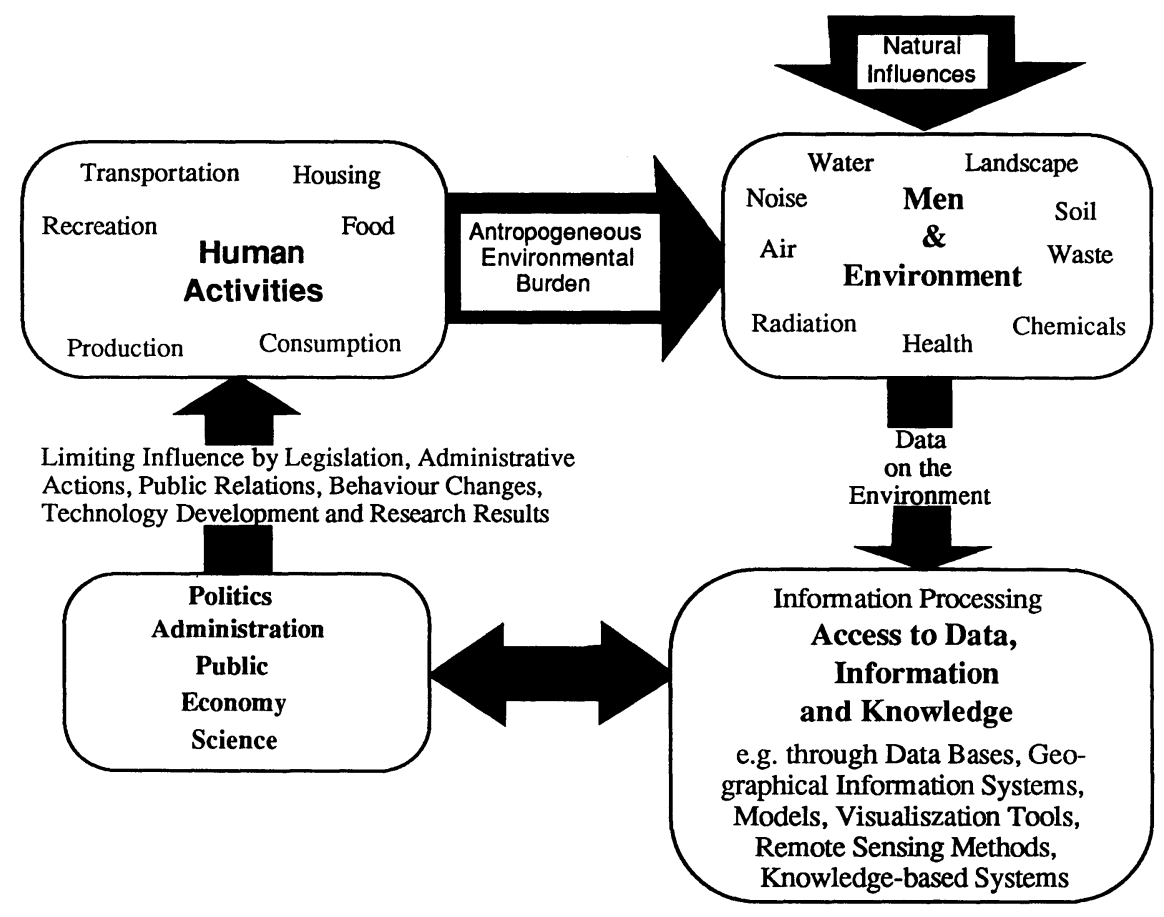

Figure 1 Potential Feedback Effects from Environmental Information Processing. 
The following trends in environmental information processing have been recently reported (Radermacher 1994; Hilty 1994a; Hilty 1995a):

- environmental monitoring by means of remote sensing and the combination of data streams from all over the world;

- a policy for sharing and integrating environmental information across political and organizational bounderies;

- advanced model-based data analysis techniques, shifting the focus from data to dynamic system structure;

- industrial applications of environmental information processing, aiming at higher ecological efficiency (resource productivity) of the economic system.

It is obvious that advanced computing technologies play an important role in these developments.

Information technology applications in the environmental domain so far have been often lacking a sound conceptual and scientific basis, since there has not been any significant research in this special domain for a long time. This is certainly not only a matter of applied Computer Science, but an interdisciplinary task where many scientific disciplines should be involved (e.g. geo- and bio-sciences, environmental engineering, economics and law, measuring technology, management sciences, etc.). On the other hand, the growing field of environmental information processing is a great challenge to Computer Science methodologies and their applications. From this process of mutual stimulation, a new discipline has been recently emerging, named as Environmental Informatics.

\section{A TYPOLOGY OF ENVIRONMENTAL INFORMATION PROCESSING SYSTEMS}

There is a wide spectrum of environmental information processing systems which can be classified based on the nature of the information and the type of processing. The typology introduced in (Page 1992a) includes monitoring and control systems, conventional information systems, computational evaluation and analysis systems, planning and decision support systems, and integrated environmental information systems:

- Monitoring and control systems: Monitoring systems deal with the automation of measurements (including remote sensing) in water, air, soil, noise, and radiation control. This also includes basic data analysis such as the aggregation of time series data, the classification of environmental objects (e.g. in satellite images), or the Identification of hazardous substances based on the measured data. Computerized process control is either directly employed in environmental technology such as in air emission control, sewage, sludge, or refuse processing, or used in production process automation with secondary effects on environmental protection (e.g. energy conservation, emission reduction). Monitoring and control systems often require the processing of vague information.

- Conventional information systems are employed for the input, storage, structuring, integration, retrieval, and the presentation of various kinds of environmental information such as raw measurement data, descriptions of environmental objects (such as geographical objects or chemical substances), as well as documents such as environmental regulations or literature references. Spatial and temporal aspects often play an important role in the manage- 
ment of these kinds of information. Various types of software tools, including geographical information systems (GIS), or relational data base systems are necessary for coping with these requirements.

- Computational evaluation and analysis systems support environmental data processing using complex numerical/statistical analysis methods and modeling techniques. This includes the simulation of various environmental scenarios. Typical applications of these systems are the identification of relevant causes of environmental impacts or the derivation of future effects of different planning measures (e.g. causal models in forest damage research or forecast of emission loads over time and region including possible counter-measures).

- Planning and decision support systems help decision makers by offering criteria for the evaluation of alternatives or for justifying decisions, e.g. for environmental impact analyses, for handling hazardous substances, for water resources management, or for technological risk assessment. For industrial applications, computer-based environmental information and management systems are currently being developed, which have to provide the environmental information processing infrastructure for industrial enterprises.

- Integrated environmental information systems cannot be uniquely related to the system types mentioned above, because they consist of multiple components serving various purposes. Many complex real world environmental information systems are of an integrated nature (e.g. a state-wide air polution information system with an automated monitoring subsystem, a measurement data base and complex statistical analysis modules with extensive graphical features). It can be expected that integrated environmental information systems will be increasingly designed as distributed systems. The integration of various concepts for information processing, which is required for building these types of systems, is a special challenge to Computer Science methodology.

\section{ENVIRONMENTAL INFORMATICS: BACKGROUND, TERMINOLOGY AND MAIN ISSUES}

\subsection{Scientific Background, Terms and Definitions}

The term "Informatics" has been introduced in Europe more than 25 years ago for the science of the fundamental methodology of information and knowledge processing, its applications as well as its implications (e.g. on the users, on the work places, on organizations - more recently also on the natural environment as shown in this ISESS conference). Many regard "Informatics" as synonymous to "Computer Science", however, it is argued here that the discipline of "Informatics" has been establishing a broader understanding. Beyond engineering aspects, Informatics is also viewing computer systems as they are embedded in organizations and in society. This is particularily true for Applied Informatics (sometimes also called "Applied Computer Science"), the branch of Informatics which bridges the gap between information technology and its various application fields.

Applied Informatics is holding a mediation role (Hilty 1995a). On one hand, it analyses realworld problems in a given application field and defines requirements on information technology. On the other hand, it introduces the problem solving potential of Informatics into the application discipline. In this way the working techniques and eventually the methodologies are 

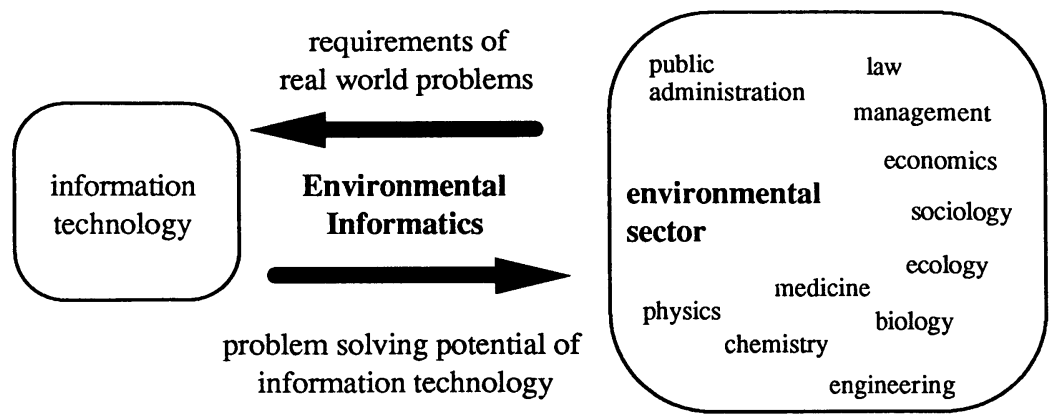

Figure 2 Environmental Informatics supports an multidisciplinary field of Information Technology applications (from Hilty 1995a).

strongly influenced or even changed in many disciplines by an intensified IT utilization. One striking example is medicine where even a completely new speciality called "Medical Informatics" was evolving out of medical computer applications as long as 20 years ago. This specialty combines expertise from Applied Informatics with medical knowledge.

A similar situation we find in the environmental sciences today leading to the formation of Environmental Informatics (Figure 2). However, we have to point out, that the environmental sector is by itself an interdisciplinary research domain. It incorporates knowledge from biology, ecology, physics, chemistry, engineering, economics, geo-sciences, management, sociology, public administration, law and medicine. This and also the fact that the younger environmental sciences have not yet achieved the level of stability of a classic science like medicine, make it more complicated, but also more challenging for Environmental Informatics to play its mediation role. The rather new term Environmental Informatics can be defined as follows (Page 1994a and 1994c):

Environmental Informatics is a subdiscipline of Applied Informatics dealing with methods and techniques of Computer Science for analysing, supporting and forming those information processing procedures contributing to the investigation, removal, avoidance and minimization of environmental burden and damages.

\subsection{Main Issues}

The claim of Environmental Informatics as a special subdiscipline of Applied Informatics of its own right can be derived from the specific characteristics of environmental data and their processing requirements typically not found in conventional information processing areas (i.e. business or administrative data processing or even in many engineering computer applications). First, we have many different, rather heterogenous data structures and information sources in environmental information systems such as text data on environmental laws or research projects, measurement data from monitoring networks, structural data on chemical substances, formated engineering data on enviromental technology, just to name a few. In particular, environmental data is often geographicaly coded, i.e. information is attached to a particular point or region in space. The represented data objects are often multidimensional and have to be de- 
scribed by means of complex geometric objects (e.g. polygons or curves). Second, the processing of empirical data with statistical methods as well as of vague, uncertain and incomplete information is a major concern in environmental informatics. Third, a comfortable user access on heterogeneous distributed environmental data bases has to be supported. Fourth, it is frequently required, to treat environmental data with model-based analyses (e.g. to recompute missing measurement values with dispersion models). And finally, environmental data must be presented and evaluated in a domain overlapping, multidisciplinary context. As a requirement, this information has to be often deducted from a number of domain specific primary data bases beforehand.

These characteristics result in different requirements on information processing in the environmental domain, i.e. firstly Environmental Informatics has to address aspects of geometric data structures and algorithms as well as of modern Geographical Information Systems (GIS). Secondly, Knowledge-based Systems are of importance in dealing with uncertain environmental knowledge. Thirdly, modeling software architectures are useful for statistical analyses as well as for environmental modeling and simulation. A key issue in Environmental Informatics is the important integration of data, information, and knowledge from various sources in the environmental sector:

- Integrating data means overcoming the heterogeneity caused by the variety of operating and database systems, data formats and documentation conventions, program interfaces and software tools, used in different organizations and disciplines.

- Integrating information means to enable data to be interpreted meaningfully in different organizational and disciplinary contexts.

- Integrating knowledge is a long-term goal aiming at the compatibility of the terminologies and conceptual frameworks of different disciplines and institutions (Hilty 1995a).

Beyond that, there are many links to heterogeneous data bases and distributed information systems, to query languages and ergonomic user interfaces, to scientific visualization of complex environmental data (see Denzer 1995) as well as to many neighbouring disciplines such as remote sensing (see Günther 1995), measuring technology or business computing.

The need for computer-based environmental management systems in industrial production is a rather new challenge to information technology (see Radermacher 1994). Information systems designed to support those actions an enterprise is taking to manage its effects on the environment are called industrial environmental information systems. With the increasing significance of industrial environmental protection as compared to the public sector, where effective environmental information systems and powerful monitoring networks are already operational or under development for some time (Page 1988; Radermacher 1994), Environmental Informatics is now looking more closely into design aspects of industrial environmental information systems (Hilty 1995b). This includes the development of computer-based ecobalances dealing with the investigation and evaluation of the total mass and energy flow of a given production process in order to assess its environmental impacts (Schmidt 1994). 


\subsection{Selected Methodologies and Research Topics}

In Environmental Informatics, a wide range of Informatics methodologies and techniques are basically applied. Here, we want to discuss in brief a few selected Informatics methodologies and research fields which we consider as particularily relevant for environmental information processing. For more details see (Page 1994b and Avouris 1995).

Database and Geographical Information Systems: Database technologies belong without any doubt to the most important tools in environmental information processing (see Page 1995). Many environmental information systems (EIS) can be considered as extended Geographical Information Systems (GIS) because of the common spatial reference of most of the data stored. On the other hand, GIS are specialised database systems for spatially structured data (see Bill 1995). Because most environmental data is related to space (i.e. geographical context), GIS are widely used as a basis for environmental information systems. However, EIS also hold thematic data (i.e. environmental facts such as measurement values or chemical substance attributes, environmental documents such as text data on research projects, laws and regulations, or literature) or data with temporal reference, respectively (e.g. land use alterations of restoration areas, or seasonal fluctuations in harmful substance measurements). GIS can neither cope with the problem of handling thematic data adequately nor of managing time series data.

The employment of traditional relational data base concepts for building up EIS is not a satisfactory solution either, because complex environmental objects such as chemical combinations, measurement series, legal documents or surface elements cannot be adequately modeled in form of normalized relations. Two important questions demanding more research in Environmental Informatics are, to what extent and how typical EIS applications can be supported by today's DBMS concepts (i.e. relational, GIS, or information retrieval systems, see Fuhr 1991) and beyond that, which DBMS concepts (e.g. data models for complex objects, or query languages with spatial/temporal predicates) should be provided by future systems in order to have an appropriate data management support to EIS applications (e.g. object-oriented database systems, see Cattel 1994; Günther 1993).

Today's environmental databases do contain a lot of raw data on many environmental aspects, however this data is often not sufficient to derive the information appropriately as requested by the user. Rather, apart from the raw environmental data also meta-information (Radermacher 1991) is required. In a broad sense, this includes information about location, time, precision, and revision dates of the data under consideration, as well as descriptions of the data structures and data formats used (Radermacher 1994). Meta-information which is necessary for an adequate interpretation of the environmental data and for user orientation in finding the relevant information sources has been missing in most existing EIS so far. Therefore, environmental meta-information systems are currently developed to overcome the prevailing lack of meta-information in the environmental sector (see Voigt 1995). They are one of the main issues to be addressed in Environmental Informatics at this time.

Modeling and Simulation: Modeling and simulation techniques have been employed in the environmental sector for more than three decades. The first applications emerged from water resource management. Today, the following types of simulation models are used for advanced data analysis tasks, for decision support, planning, or for process control: 
- Dispersion and quality models for air, water, or soil (e.g. Sydow 1994; Fedra 1994)

- Ecosystem models and models in ecological economics (e.g. Bossel 1994a and1994b),

- Process models as a part of process control systems (e.g. Gilles 1988),

- Models for the prediction of traffic emissions (e.g. Häuslein 1994) and for planning purposes in "eco-logistics" (e.g. Hilty 1994b).

The task of Environmental Informatics in environmental modeling is to provide adequate tools that enable users to build simulation models with not too much effort, i.e. by using graphical modeling languages, modeling and simulation program packages or simulation systems, which provide standard modules that can be used as "building blocks" for modeling (see also Häuslein 1994 and section 4 of this paper).

Computer Graphics and Visualization: Employing computer graphics methodology for scientific visualisation of compex environmental data is significant because there is still a lack of knowledge about causal relationships and regularities in environmental systems. In this situation visualization is an important means for transparent data analysis and for the identification of previously unknown structures.

Moreover, graphical presentations are well suited to communicate environmentally relevant facts to decision-makers and to the public (see also Denzer 1995).

Knowledge-based Systems: More recently knowledge-based systems, in particular expert systems or Neuronal Nets (Keller 1995), were also applied to environmental information processing. Knowledge-based approaches are especially relevant for the interpretation of image data from monitoring systems such as aerial photographs and satellite sensor data. They can also be used in supporting environmental modeling and simulation studies (see section 4).

Expert systems have been developed for decision support or planning applications in the following environmental domains (Page 1990; Simon 1995):

- Waste disposal, evaluation of hazardous substances and contaminated sites,

- Environmental impact assessment and environmental planning,

- Application of environmental laws, regulations, and technical instructions,

- Advice in accidents and emergency situations with hazardous chemicals.

However, most of these projects have not yet advanced beyond the prototype state. The utilization of expert system technology in the environmental domain has been limited todate, because

- the spatial and temporal reference of most environmental problems require substancial advances in spatial and temporal reasoning methods,

- the realtime capability of expert systems is not sufficient yet for many environmental monitoring and environmentally adapted process control applications,

- the integration of expert system techniques with conventional system components (i.e. data bases, geographical information systems, simulation models) has to be improved,

- knowledge aquisition techniques and tools for multidisciplinary knowledge domains such as environmental sciences have to be refined. In this way, domain knowledge from experts of different disciplines has to be aquired and synthezised. 
- model-based reasoning is more promising for some environmental domains (e.g. technical diagnosis for wastewater treatment plants, or ecosystem analysis) than straigthforward rulebased techniques, found in most conventional ("flat") expert systems (Page 1990).

Systems Integration: As already mentioned in section 3.2, integration is one key issue in Environmental Informatics, and it entails more than purely technical problems. The harmonization of environmental information at national, international, or even worldwide levels is of central importance for gaining a reliable reporting system on the state of the environment. These requirements, however, are confronted with the existing heterogeneity of the different standards, terms and measuring methods in the environmental field as well as of hardware and software environments, database systems, method and model bases, network technology, and programming languages. Approaches for overcoming the heterogeneity, one of the major obstacles to open software solutions, can have a tremendous impact on the productivity in environmental management, and can also lead to a greater stability in system design and system usage in environmental information processing (Riekert 1994; Hilty 1995a).

One possible approach to cope with heterogenous system components could be the installation of meta-information servers to facilitate access to distributed information systems which has already proven to be very useful for the integration of monitoring data from different sources (Schimak 1994).

\section{AN ENVIRONMENTAL INFORMATICS RESEARCH AND DEVELOPMENT PROJECT: A KNOWLEDGE-BASED SIMULATION FRAME SYSTEM FOR PROTOTYPING ENVIRONMENTAL MODELING TOOLS}

\subsection{Background}

Modeling environmental systems (e.g. road traffic pollution) requires powerful software tools which account for the heterogeneous environmental domain with a wide range of modeling methodologies involved and for non-technical user groups with only limited background in modeling and computing.

Road Traffic is known as one of the most critical sources of environmental problems. Frequently rather rough, highly aggregated traffic emission models are developed on the national scale for governmental decision support by the German Federal Environmental Agency (Umweltbundesamt) aiming at the estimation of future road traffic development, of future pollutant emissions, and at the analysis of alternative traffic development scenarios (e.g. laws, regulations, technical standards, taxation measures, new engine technologies). The modeling follows a rather straightforward approach based on statistical time series data easily available at the time of governmental request (usually on short notice). Typically the models are "throw away"-models not very suitable for later use after the completion of the current investigation. Because the computations were quite simple, spread sheet programs were used. However, when the models grew larger the limitations of these tools became obvious (e.g. lack of model transparency and extensionabilty). 
It was realized that a new, more flexible modeling tool was required for coping with the increased complexity and number of modeling activities for road traffic emission forecasting in the Federal Environmental Agency. Along with the development of a more flexible and transparent modeling tool a generalized, better structured modeling approach was striven for. A selfmade adaptable simulation system was employed in this applied research project to develop a new table-oriented modeling approach for road traffic emissions based on statistical time series data and for prototyping an appropriate modeling tool of higher flexibility and transparency for this specific modeling domain. The project was sponsored by the German Federal Environmental Agency.

\subsection{A Knowledge-based Simulation System as Development Tool}

A simulation tool named DYNAMIS IIx was developed at the University of Hamburg as a research prototype. It is gaining its flexibility from making use of object-oriented and knowledge-based techniques and was aimed at improving user support and modeling flexibility at the same time (Häuslein 1993). This includes comfortable graphical modeling, hierarchical model design with any number of aggregation levels, provision of simulation specific knowledge, powerful internal model representation (also including non-numerical knowledge), model management facilities, selection from different simulation methodologies in the system, uncomplicated system extensions by additional simulation methods, or manifold model utilization, respectively.

Graphical Modeling: Model structure is presented graphically by a model diagram in a special system diagram window. The diagram is built up by selecting predefined model variable symbols from a menu under mouse control and by linking them through connecting lines in a way consistent with the given simulation methodology. Thereby, a significant part of model design is carried out on the graphical level. The equations for the model variables required for specifying the complete mathematical model definition are edited in a different window - the content window - existing for particular diagram symbols (i.e. model variables) and opened by clicking on the related symbol of the diagram. Numerical values and arithmetic expressions are entered for describing dynamical behavior on the respective model variables. Quite often this information is already inherent in the model structure diagram and can therefore be generated automatically. In this case, it only has to be interactively supplemented by the modeler. The system also allows for the introduction of user defined, application specific graphical notations (e.g. tree or vehicle icons) to account for the needs of non-technical user groups in certain application areas. The redefinition is only addressing the external model representation and has no impact on the internal system level.

Graphical modeling offers a descriptive and intuitive access to model building from the user point of view. Graphical models can be constructed without programming effort and proficiency. Model diagrams are supporting model documentation already in early model building stages and allow for an easier model understanding by outside users.

Hierarchical Modeling: Another important system feature is the support of modular, hierarchical model construction which proved to be very helpful in the environmental field for building comprehensive environmental models out of separate model building blocks. Each model can be embedded in another model as a submodel. A model interface is generated for 
each submodel where its external relations to the higher level model or other submodels are defined. In this way, a model can be constructed from other (sub) models across any number of aggregation levels. With this approach supported by an appropriate model management facility the utilization of already existing models as model components is promoted.

Knowledge-based Support: Simulation specific knowledge is included in the simulation system making use of knowledge-based techniques to support inexperienced users in model building proficiency. Knowledge bases provided by the system incorporate knowledge on given simulation methodologies (i.e. knowledge on methodologically correct model construction). This knowledge is represented as assertions and rules. It is provided to the user in different forms. User actions are checked for consistency with these rules during the model building process. This includes the model symbol placement and the line connections; e.g. not all model variables are combinable with each other or can be only connected with special links. Rule violation, i.e. an inconsistency with simulation methodology, leads to warnings or even user action breakoffs in severe cases. With the explanation facility of the embedded expert system shell further comments can be generated explaining the error sources in more detail and giving alternative advice. Beyond the consistency check for each model symbol linked into the model diagram during stepwise model building correctness of the overall model is established before the simulation run is actually started. Here model completeness is analysed, i.e. whether all required variables and links have been specified in the appropriate manner. Other points in the checking procedure concern unique naming conventions for model variables as well as the existence of cycles in model links.

In addition, a model specific knowledge base is established for each model where declarations on the model and its components are entered by the system during the model building process. This knowledge can be retrieved by simple queries or used for deriving new knowledge depending on the available rule set. Thus, it will be possible to make earlier use of knowledge already present in the model for inferences well before a complete numerical model definition. In this way, we allow for an incremental model construction by exploiting inherent model knowledge making inferences on the model long before a mathematical solution (e.g. of differential equations) becomes feasible (Häuslein 1991).

System Extensionability: The employment of object-oriented approaches in system architecture and implementation as well as the integration of an expert system shell allow for high flexibility in system utilization and extension as well as for user support in model building. It includes several different simulation methodologies relevant to environmental modeling (e.g. System Dynamics or Energy-Flow-Models) and offers advice on their employment under specified conditions. The integration of additional simulation methodologies into the running system has been one of the main design goals and therefore has been taken care of in the system architecture; i.e. system extensions for new simulation methodologies are realized by using and supplementing a predefined class hierarchy of model objects based on the inheritance principle.

System architecture (see Figure 3) is characterized by three different layers, each incorporating respective functionality of a given type. First, there is an external layer with all functions serving for model user interface generation and in particular for graphical model presentation in diagram form. The internal layer specifies model contents independently from their external representation form, i.e. it takes care of model evaluation and simulation processing. The 


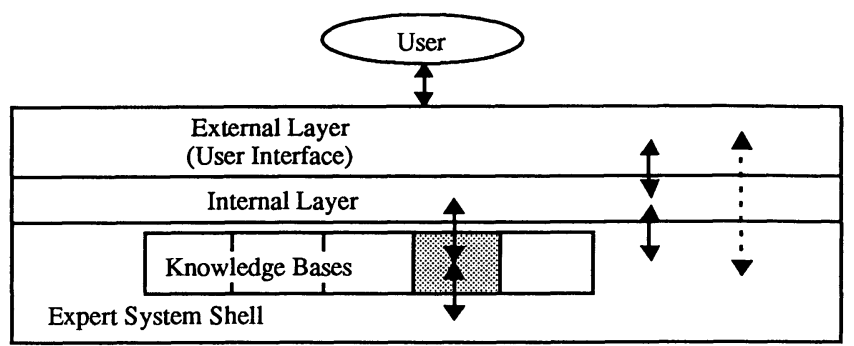

Figure 3 General Architecture of the Knowledge-based Simulation System DYNAMIS IIx

knowledge-based layer incorporates special knowledge on model construction, correctness and classification in several model bases as stated above. Knowledge-based functions are provided by an embedded expert system shell not directly visible on the user interface. The user is working with one homogeneous simulation system from his point of view.

Basic functionality is offered by a system kernel on any layer with all relevant system functions independently of a particular simulation methodology. On each layer the system kernel consists of an object class hierarchy with related methods. In this way, a simulation frame system is provided which can be extended for serving concrete simulation methodologies by limited supplements. The extension of the frame system with objects and methods required for supporting a special simulation method can be easily implemented by refering to the available basic object classes and their methods making use of the inheritance mechanism in objectoriented programming (the system was implemented in Allegro Common Lisp with Object Lisp on an Apple Macintosh).

The separation into three system layers facilitates the simulation system extension and modification. Changes can be carried out at the different layers without affecting the other layers. In integrating new simulation methodologies it might well be sufficient to exchange the graphical notation on the external level, introduce a few supplements to the existing object classes on the external level and to substitute the methodological knowledge base. Therefore the simulation system seems well suited for prototying new modeling tools.

\subsection{The Prototype Modeling Tool for Road Traffic Emissions}

Requirements: The construction of models for road traffic emission analysis can be facilitated by an appropriate software tool meeting a number of basic requirements from this modeling domain. The tool has to provide powerful table processing facilities, since the methodology for road traffic emission on the national scale is basically table-oriented, i.e. supporting input of empirical table data, the generation of new tables and the combination of table values. Model building should go hand in hand with an automatic consistency check relating to the modeling methodology, with a clear representation of model structure in graphical form, and should allow for the processing of historical as well as prognosis data, an easy model adaptability and straightforward formula checks. Also there was a requirement for a clear graphical presentation and a structured organization and documentation of simulation results with an interactive selection and output of single model variable dynamics. 
The Modeling Approach: Since the data in the field of road traffic emission modeling is typically found in tabular form, the modeling approach to be employed had to take account for the construction and arithmetic manipulation of tables. A new flexible modeling approach named "Dynamic Relations" was introduced combining tabular operations with graphical modeling. The basic concepts for the utilization of tabular data structures ("relations") have been well established in data base theory for a long time already ("Relational Algebra"). We adopted a wide range of these relational operations for the modeling approach, however, we take a different view on relations by adding another dimension - the time axis. We supplement the relational operations with some handy functions for arithmetic operations on column values. We introduce interpolation as well as prognosis functions to account for missing or future values, respectively. In this way a simulation run is on one hand reproducing historical progress (e.g. of past emission development) on the basis of empirical time series data (e.g. on vehicle stock, type distribution or mileage) and is on the other hand constructing future scenarios by performing projections and prognoses.

The modeling operations defined in the "Dynamic Relations"-Approach allow for the combination of tables, the arithmetic computation of value sets, the projection and selection of tables as well as the aggregation and grouping of values. The behavior of model variables is specified in definitions, i.e. mathematical expressions evaluating to table constructions. Links in the model diagram describe value flows between model variables. The values of input tables are already available on external files at the start of a simulation, the other model variables generate their specific values by evaluating their definition time step by time step during a simulation run. An overview of the model variables in the "Dynamic Relations"-Approach including the graphical symbols is given in Figure 4. The methodology was implemented as special system extension of the knowledge-based simulation tool DYNAMIS IIx introduced above.

\begin{tabular}{|l|ll|}
\hline Computational Table & Combination of Tables & \\
\hline Input Table & Loading of external Data & \\
\hline Key & Construction of Key Expression & \\
\hline Selector & Selection and Projection & \\
\hline Output-Selector & Presentation of a Value Set as Curve \\
\hline Operation Instruction & Construction of arithmetic Expression \\
\hline Operator & $\begin{array}{l}\text { Arithmetic Combination of different Table } \\
\text { Columns }\end{array}$ & \\
\hline Aggregator & Aggregation of Table Rows & \\
\hline Submodel & $\begin{array}{l}\text { Separation into Submodels (hierarchical } \\
\text { Modeling) }\end{array}$ \\
\hline Inout & Communication between Submodels \\
\hline
\end{tabular}

Figure 4 Modeling Components of "Dynamic Relations"-Approach 


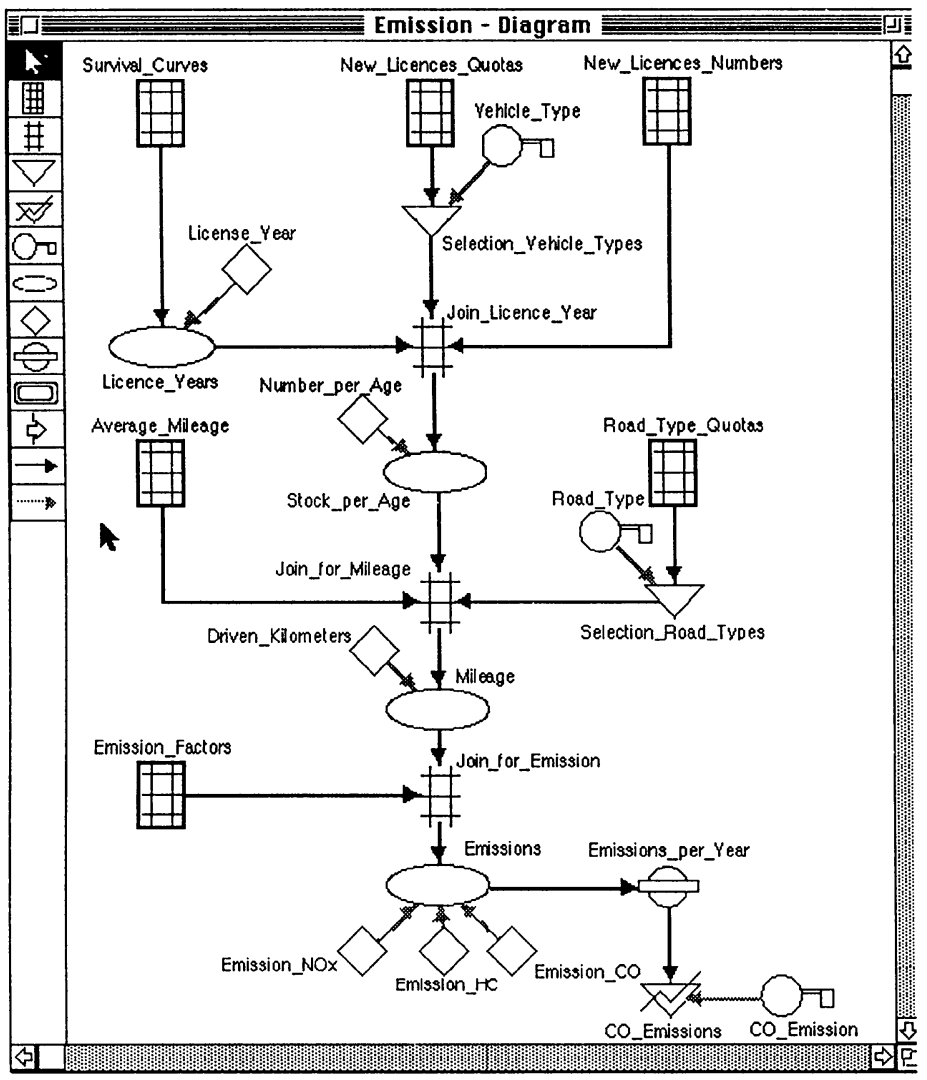

Figure 5 "Dynamic Relations"- Model Diagram for Road Traffic Emission Model

A Road Traffic Emission Model: A rather straightforward emission model for the private car sector in the Federal Republic of Germany for the years 1965 to 2010 was then set up to demonstrate the table-oriented, graphical modeling methodology just introduced (see Figure 5). Input tables include vehicle survival curves, new licence quotas, vehicle type quotas, milage, road types, and emission factors. The dynamic emission computation is carried out in three main steps each producing a new table, i.e. motor vehicle stock (classified by vehicle type and age from survival quotas, licence quotas and overall new licences), mileage per year (for reference year from average mileage classified by vehicle type, age and road type) as well as emissions (per pollutant by multiplication of driven kilometers with emission factors). The model is reproducing or forecasting, respectively the development of the pollutant emissions over the years under consideration. Model results would be produced interactively showing emission curves for different pollutants at the display in the course of the simulation. More model detail could be incorporated without much effort as improved and more differentiated 
data become eventually available. It would only involve slight changes to introduce refined classifications (i.e. extended tables) or additional types of model variables (e.g. tables with driving cycles).

Assessment: It can be concluded that in the course of the project the research prototype simulation tool with its object-oriented and knowledge-based architecture proved to be a very powerful and flexible prototyping tool for designing special modeling software (Häuslein 1995). From our point of view the "Dynamic Relations"-approach estalished in this project is well suited for table-oriented traffic emission modeling, but its applicability has definitely a much wider scope.

\section{THE EVOLVING RESEARCH SCENE IN GERMANY}

Scientific Associations and Publications: The new discipline of Environmental Informatics has been maturing since the mid-eighties. In Germany, this is well documented by the proceedings of the annual conferences which have been organized by the Special Interest Group "Informatics in Environmental Protection" in the German Society for Informatics (Gesellschaft für Informatik - GI). This very dedicated group started its activities already back in 1987 and has now around 900 members. A number of working groups have been established dealing with special aspects of environmental information processing such as Environmental Databases, Visualization of environmental Data, Methods and Tools for environmental Impact Assessment, Integration of environmental Data, Tools for environmental Modeling and Simulation and more recently Industrial environmental Information Systems - just to name some of the working groups.

The anual conferences and a number of additional workshops have yielded a growing number of participants, projects, and publications (e.g., Jaeschke 1987a and b; Valk 1988; Jaeschke 1989; Pillmann 1990; Hälker 1991; Denzer 1992; Jaeschke 1993). Only last year an own book series for the publications of the special interest group has been arranged by a publisher (see Hilty 1994a).

The German Federal Environmental Office is operating an online database "Environmental Literature" and has established an own section "Environmental Data Processing and Informatics" already in 1988. Since then, the relevant German and also selected English publications in this field are registered on a regular basis. An extract of this database section was documented in a bibliography (Umweltbundesamt 1989).

Only recently an own volume "Environmental Informatic up to date" was published in the renowed German Series "Handbook of Informatics" (Page 1994b) and in this way it is documented that our discipline has been accepted now as one of the established Informatics branches. Beyond that, the German Society for Informatics has claimed the issue "Informatics and the Environment" as one of their two central themes for the future (together with "Informatics and Mobility"; see Jeaschke 1994). Thus, we argue that Environmental Informatics is now recognized as integral part of Applied Informatics in Germany.

Education: A few professional schools in Germany are offering continueing education programs in Environmental Information Processing. On the academic level the Department of Informatics at the University of Hamburg has, as the first university in Germany, just started a 
new elective "Methods of Informatics for Environmental Protection" within the Applied Informatics specialization of the Informatics degree program.

Internationalization: The International Federation for Information Processing (IFIP) has established a working group for this application field (WG 5.11 "Computers and the Environment") in 1992, where members of the German Special Interest Group are playing an active role. The first iniative was a workshop "Informatics for Environmental Protection" at the 12th World Computer Congress in Madrid, Spain in September 1992 (Aiken 1992). In the following year a more specialized working conference was held at Como, Italy dealing with "Computer Support for environmental Impact Assessment". (Guariso 1994) drawing an international participation from more than 15 countries. On the 13th IFIP World Computer Congress in Hamburg, Germany in 1994 a few papers and a panel discussion also focused on environmental information processing aspects (e.g. Radermacher 1994; Hilty 1994c). The new book "Environmental Informatics - Methodology and Applications of Environmental Information Processing" published by Kluwer Academic in English in 1995 (Avouris 1995) - and not to forget this ISESS conference - will eventually promote further the international attention on the new field of Environmental Informatics.

\section{CONCLUSIONS AND OUTLOOK}

Environmental Informatics has now become an integral part of Applied Informatics. Its special characteristic is the transformation of Computer Science methodologies into the application field environmental protection. On one hand, Environmental Informatics has a problem solving potential that must be developed into practical solutions for environmental information processing problems. On the other hand, new and challenging requirements arise in the environmental sector that stimulate research and development in Informatics methodology and applications. The main challenge to Informatics is the complexity and heterogeneity of the environmental sector, demanding for innovative approaches to control complexity and to integrate existing data, information, and knowledge from various scientific disciplines and organizations (Hilty 1995a). It has to be stressed, however, that Environmental Informatics does not only explore the potential benefits of information technology for contributing to the solution of environmental problems, but also sees its responsibility to consider the negative environmental impacts of IT (Rolf 1994).

Also, the role of Environmental Informatics should not be restricted to computer-based investigation of the present state of the environment. Applying sophisticated computing methodologies just to cure at symptoms of our environmental crisis is certainly not enough. Since the Rio Summit has accepted the model "sustainable development", meaning a way of living and a form of using resources that does not discriminate against future generations (WCED 1987), there seems to be now a rewarding framework and direction also for our future work at hand. Although it is certainly difficult to operationalize this model, it is clear that providing adequate information will be an important step towards changing attitudes and making decisive political actions into that direction possible (Friend 1991). Thus, Environmental Informatics should also accept the challenge to play an active role in the local and global transformations that will be needed to approach sustainability (Hilty 1994c; Rolf 1994). 


\section{REFERENCES}

Aiken, R.M. (eds.) (1992) Education and Society. Information Processing 92. Symposium 2: Informatics for Environmental Protection. IFIP Transactions A-13.Vol. II, pp. 593-686. Amsterdam: North-Holland.

Avouris, N., Page, B. (eds.) (1995) Environmental Informatics - Methodology and Applications of Environmental Information Processing. Kluwer Academic Publishers, Dordrecht, Netherlands.

Bill, R. (1995) Spatial Data Processing in environmental Information Systems, in Environmental Informatics - Methodology and Applications of Environmental Information Processing (eds. N. Avouris, B. Page), pp. 53-73.

Bossel, H. (1994a) Modeling and Simulation. A. K. Peters, Wellesley MA.

Bossel, H. (1994b) Understanding Dynamic Systems: Shifting the Focus from Data to Structure, in Informatik für den Umweltschutz (eds. L.M. Hilty, A. Jaeschke, B. Page, A. Schwabl), Proc. 8. Symposium, Hamburg 1994, Volume I, pp. 63-75.

Cattel, R.G.G. (1994) The Object Database Standard: ODMG-93. Morgan Kaufmann.

Denzer, R., Schimak, G., Haas, W. (eds.) (1992), Visualisierung von Umweltdaten. Proceedings 3. Workshop, Schloß Zell an der Pram, Dezember 1992. Informatik Aktuell, Berlin, Springer.

Denzer, R., Mayer, H.F., Haas, W. (1995) Visualisation of environmental Data, in Environmental Informatics - Methodology and Applications of Environmental Information Processing (eds. N. Avouris, B. Page), pp. 75-92.

Fedra, K. (1994) Model-based Environmental Information and Decision Support Systems, in Informatik für den Umweltschutz (eds. L.M. Hilty, A. Jaeschke, B. Page, A. Schwabl), Proc. 8. Symposium, Hamburg 1994, Volume I, pp. 37-58.

Friend, A.M., Rapport, D.J. (1991) Evolution of macro-information systems for sustainable development. Ecological Economics, 3/1991, pp. 59-76.

Fuhr, N. (1991) An Information Retrieval View of Environmental Information Systems, in DEXA 91, Proc. 2nd Intern.Conf. on Data Base and Expert System Applications, Berlin: Springer.

Gilles, E.D., Marquardt, W. (1988) Prozeßsimulation - ein Beitrag zum aktiven Umweltschutz, in Beitrag der Mikorelektronik zum Umweltschutz, Proceedings, GMEFachbericht. Berlin: vde-Verlag.

Guariso, G., Page, B. (eds.) (1994) Computer Support for Environmental Impact Assessment. IFIP Transactions B-16. Amsterdam: North-Holland.

Günther, O., Riekert, W.-F. (1993) The Design of GODOT: An Object-Oriented Geographic Information System, IEEE Data Engineering Bulletin 16(3), September 1993.

Günther, O., Radermacher, F.J., Riekert, W.-F. (1995) Environmental Monitoring: Models, Methods ans Systems, in Environmental Informatics - Methodology and Applications of Environmental Information Processing (eds. N. Avouris, B. Page), pp. 13-38.

Hälker, M., Jaeschke, A. (ed.) (1991) Informatik für den Umweltschutz - Computer Science for Environmental Protection. Proceedings 6. Symposium München, Dezember 1991, Informatik-Fachberichte 296, Berlin: Springer.

Häuslein, A., Page, B. (1991) Knowledge-based Approaches to Modeling and Simulation Support, in Systems Analysis, Modeling and Simulation 8, 4/5, (1991), pp. 257-272. 
Häuslein, A. (1993) Wissensbasierte Unterstuetzung der Modelbildung und Simulation im Umweltbereich - Konzeption und prototypische Realisierung eines Simulationssystems. Europaeische Hochschulschriften, Series XLI Informatics, Vol. 12, Frankfurt: Peter Lang Publ.

Häuslein, A., Page, B. (1994) Prototyping environmental Modeling Tools with a knowledgebased Simulation Frame System, in Proc. 14th IMACS World Congress on Computation and Applied Mathematics. Atlanta, Georgia, July 11-15, 1994, Vol. 3, Atlanta: Georgia Institute of Technology, p.1271-1276.

Häuslein, A., Page, B. (1995) A knowledge-based Simulation Kernel System for the Design of environmental Modeling Tools, in Environmental Informatics - Methodology and Applications of Environmental Information Processing (eds. N. Avouris, B. Page), pp. 147-160.

Hilty, L.M., Jaeschke, A., Page, B., Schwabl, A., (eds.) (1994a) Informatik für den Umweltschutz, 8. Symposium, Hamburg 1994. Marburg: Metropolis.

Hilty, L.M., Martinssen, D., Page, B., (1994b) Designing a Simulation Tool for the Environmental Assessment of Logistical Systems and Strategies, in (Guariso 1994).

Hilty, L.M., Weiland, U. (1994c) Sustainable Cities - Opportunities and Risks of Information Technology, in Proceedings of the 13th World Computer Congress (Brunnstein, K.; Raubold, E. (eds.)) Volume II: Applications and Impacts. Amsterdam: Elsevier. pp. 613-618.

Hilty L.M., Page, B., Radermacher, F.J., Riekert, W.-F. (1995a) Environmental Informatics as a new Discipline of Applied Computer Science, in Environmental Informatics Methodology and Applications of Environmental Information Processing (eds. N. Avouris, B. Page), pp. 1-11.

Hilty, L.M. (1995b) Information systems for industrial environmental Management, in Environmental Informatics - Methodology and Applications of Environmental Information Processing (eds. N. Avouris, B. Page), pp. 371-384.

Jaeschke, A., Page, B. (eds.) (1987a) Kolloquium: Informatikanwendungen im Umweltbereich. Kernforschungszentrum 1986, KfK-Bericht 4223, Karlsruhe.

Jaeschke, A., Page, B. (eds.) (1987b) Informatikanwendungen im Umweltbereich. Proc. 2. Symposium, Karlsruhe 1987, Informatik-Fachberichte 256, Berlin: Springer Verlag.

Jaeschke, A., Geiger, W., Page, B. (eds.) (1989) Informatik im Umweltschutz. Proc. 4. Symposium, Karlsruhe, 6.-8. November 1989, Informatik-Fachberichte 228, Berlin: Springer-Verlag.

Jaeschke, A., Kämpke, T., Page, B., Radermacher, F.J.(eds.) (1993) Informatik für den Umweltschutz. Berlin: Springer-Verlag.

Jaeschke, A.(ed.) (1994) Schwerpunktthema Umweltinformatik, it+ti 4/5 94. München: Oldenburg-Verlag, pp. 9-61.

Keller, H.B. (1995) Neural Nets in Environmental Applications, in Environmental Informatics - Methodology and Applications of Environmental Information Processing (eds. N. Avouris, B. Page), pp. 127-145.

Page, B. (1988) Environmental Computing - Status and Research Perspectives, in Computer Techniques in Environmental Studies (Zanetti, P. (eds.)), Proc. ENVIROSOFT 88, 2nd Intern. Conf., Porto Carras, Greece, Sept. 1988, SouthhamptonBoston: Computational Mechanics, pp. 597-607.

Page, B.(1990) An Analysis of Environmental Expert Systems. Environmental Software, Vol. 5/1990, No. 4, pp. 177-198. 
Page, B. (1992a) Environmental Protection as a Challenge to Applied Informatics -A Workshop Introduction, in Education and Society (Aiken, R. (eds.)), Information Processing 92, Volume II. Elsevier Science Publishers B.V. (North Holland), pp. 595-604.

Page, B. (1994a) Umweltinformatik - Eine neuartige Fachdisziplin der Angewandten Informatik für den Umweltschutz, in Umweltinformationssysteme in der öffentlichen Verwaltung (Engel, A. (eds.)), Heidelberg: R.v.Decker's Verlag, pp. 23-47.

Page, B., Hilty, L.M. (eds.) (1994b) Umweltinformatik - Informatikmethoden für Umweltschutz und Umweltforschung. Handbuch der Informatik, Band 13.3. München, Wien: R. Oldenbourg Verlag.

Page, B., Hilty, L.M. (1994c) Umweltinformatik als Teilgebiet der Angewandten Informatik, in Umweltinformatik - Informatikmethoden für Umweltschutz und Umweltforschung (eds. B. Page, L.M. Hilty), Handbuch der Informatik, Band 13.3., pp. 13-26.

Page, B. (1995) Database Technologies for Environmental Data Management, in Environmental Informatics - Methodology and Applications of Environmental Information Processing (eds. N. Avouris, B. Page), pp. 39-51.

Pillmann, W., Jaeschke, A. (eds.) (1990) Informatik für den Umweltschutz. Proceedings 5. Symposium, Wien, September 1990, Informatik-Fachberichte 256, Berlin: SpringerVerlag.

Radermacher, F.J., Riekert, W.-F., Page, B., Hilty, L.M. (1994) Trends in Enviromental Information Processing, in Applications and Impacts (Brunnstein, K., Raubold (eds.)) IFIP Transactions A-52. Amsterdam: North-Holland.pp. 597-604.

Radermacher, F.J. (1991) The Importance of Metaknowledge for Environmental Information Systems, in Large Spatial Databases (Günther, O., Schek, H.-J. (eds.)), Proc. Lecture Notes in Computer Science 525, Berlin: Springer-Verlag, pp. 35-44.

Riekert, W.-F., Henning, I., Schmidt, F. (1994) Integration von heterogenen Komponenten des Umweltinformationssystems (UIS) Baden-Württemberg, in 2. Workshop „Integration von Umweltdaten ", KfK-Bericht 5314, Kernforschungszentrum Karlsruhe.

Rolf, A., Hilty, L.M. (1994) Orientierungen für die Umweltinformatik, in (Page 1994b, pp. 257-270).

Schimak, G., Humer, H. (1994) The Ozone Network for Austria - Technical Concept of a Distributed Environmental Information System, in Informatik für den Umweltschutz (eds. L.M. Hilty, A. Jaeschke, B. Page, A. Schwabl), Proc. 8. Symposium, Hamburg 1994, Volume I, pp. 89-96.

Schmidt, M., Giegrich, J., Hilty, L.M. (1994) Experiences with ecobalances and the development of an interactive software tool, in Informatik für den Umweltschutz (eds. L.M. Hilty, A. Jaeschke, B. Page, A. Schwabl), Proc. 8. Symposium, Hamburg 1994, Volume I, pp. 101-108.

Simon, K.-H., Jaeschke, A., Manche, A. (1995) Environmental Applications of Expert System Technology, in Environmental Informatics - Methodology and Applications of Environmental Information Processing (eds. N. Avouris, B. Page), pp. 93-109.

Sydow A., (1994) Smog Analysis by Parallel Simulation, in Informatik für den Umweltschutz (eds. L.M. Hilty, A. Jaeschke, B. Page, A. Schwabl), Proc. 8. Symposium, Hamburg 1994, Volume I, pp. 59-61.

Umweltbundesamt (ed.) (1989) Bibliographie Umwelt-Informatik. Berlin: Erich Schmidt Verlag. 
Valk, R. (ed.) (1988) Vernetzte und komplexe Informatik-Systeme. Fachgespräch "Informatikanwendungen im Umweltbereich". Proc. 18. Jahrestagung der Gesellschaft für Informatik (GI), Hamburg Oct. 1988, Informatik-Fachberichte 187, Berlin: Springer Verlag, pp.187-380.

Voigt, K., Bruggermann, R. (1995) Meta Information System for environmental Chemicals, in Environmental Informatics - Methodology and Applications of Environmental Information Processing (eds. N. Avouris, B. Page), pp. 315-336.

WCED - World Commission on Environment and Development (1987) Our Common Future, Oxford: Oxford University Press.

\section{BIOGRAPHY}

Dr. Bernd Page graduated from the Technical University of Berlin and Stanford University and is now a professor for Applied Informatics at the University of Hamburg, Germany where he is doing research and teaching in simulation and environmental information systems. Before his appointment in 1984 he has been working as a scientific associate in the Environmental Information System Group at the German Federal Environmental Office. He received a number of research and development grants and has published extensively in the field of environmental information processing. Dr. Page is co-founder and chairman of the Special Interest Group "Informatics for Environmental Protection" in the German Computer Society (GI) and vice chairman of the IFIP-Working Group 5.11 "Computers and the Environment". 